\title{
Smoking habit and chemo-radiotherapy and/or surgery affect the sensitivity of EGFR plasma test in non-small cell lung cancer
}

\author{
Vinh Thanh Tran ${ }^{1}$, Thang Thanh Phan ${ }^{1,2^{*}}$ (D), Son Truong Nguyen ${ }^{1,3}$, Bich-Thu Tran², Toan Trong Ho ${ }^{1}$, \\ Suong Phuoc Pho ${ }^{1}$, Tran Bao Nguyen ${ }^{1}$, Tuyen Thi Bich Pham ${ }^{1}$, Anh Tuan Le ${ }^{4}$, Vu Thuong Le ${ }^{5}$ \\ and Hang Thuy Nguyen ${ }^{6}$
}

\begin{abstract}
Objective: This study aimed to identify the influential factors for the sensitivity of epidermal growth factor receptor (EGFR) plasma test in non-small cell lung cancer (NSCLC). The mutations were detected in tumor tissue and matched plasma samples from 125 newly diagnosed adenocarcinoma, clinical-stage IIIB-IV patients, and compared the diagnostic values of EGFR plasma test between groups of clinical characteristics. The influential factors for the sensitivity were identified and assessed by logistic regression.

Results: EGFR mutations were detected in 65 (52.0\%) tumor tissue and 50 (40.0\%) matched plasma samples $(P=0.028)$. Compared to the tissue method, the concordance rate, sensitivity, and specificity of the EGFR plasma test were $86.4 \%, 75.4 \%$, and $98.3 \%$, respectively. Notably, we found that sensitivity of the test is higher in non-smokers (84.1\%) compared to smokers $(57.1 \%, P=0.018)$, and in treatment naïve subjects (85.7\%) compared to whom undergone chemo-radiotherapy with/without surgery before testing $(56.5 \%, P=0.009)$. Furthermore, the highest sensitivity was attained in patients without these two factors (90.3\%), whilst the lowest value was noted in those with both factors $(40.0 \%, P=0.004)$. The multivariable analysis confirmed that smoking habit and treatment history have independently negative impacts on sensitivity $(\mathrm{OR}=0.24, P=0.019$, and $\mathrm{OR}=0.36, P=0.047$, respectively).
\end{abstract}

Keywords: EGFR mutations, cfDNA, NSCLC, Sensitivity

\section{Introduction}

After the breakthrough of using EGFR tyrosine kinase inhibitors in treatment for NSCLC, EGFR mutation testing in the non-invasive samples as peripheral blood has opened a new period of precision medicine. More than thirty studies have been conducted in the past 15 years to assess the diagnostic values and applicability of this test in clinical practice [1-6]. Most of them have shown that the specificity of the EGFR blood test is quite high (95-98\%)

\footnotetext{
*Correspondence: thanhthangphan@gmail.com

1 The Laboratory D Unit, Clinical Cancer Center, Cho Ray Hospital, 201B

Nguyen Chi Thanh Street, Dist. 5, Ho Chi Minh City 700000, Vietnam

Full list of author information is available at the end of the article
}

[1]. However, the agreement of results in plasma with the tumor tissue is widely-fluctuated (66-100\%) [1-6]. Also, the sensitivity of the EGFR plasma test is very different between laboratories and areas (17-100\%) [1-6]. Some factors have been shown to influence the sensitivity and accuracy of the test like method of circulating free DNA (cfDNA) extraction and mutation detecting, sample type, sample volume, and processing method [1,7-9]. We assume that other clinical factors also affect the concordance rate and sensitivity of the test. In the laboratory setting, we use a high-throughput system together with a recommended protocol to isolate cfDNA $[7,8]$, and scorpion amplification-refractory mutation system (scorpion ARMS) to detect EGFR mutations, and compare the

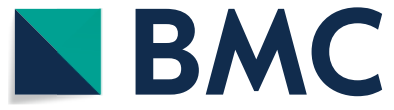

(c) The Author(s) 2020. This article is licensed under a Creative Commons Attribution 4.0 International License, which permits use, sharing, adaptation, distribution and reproduction in any medium or format, as long as you give appropriate credit to the original author(s) and the source, provide a link to the Creative Commons licence, and indicate if changes were made. The images or other third party material in this article are included in the article's Creative Commons licence, unless indicated otherwise in a credit line to the material. If material is not included in the article's Creative Commons licence and your intended use is not permitted by statutory regulation or exceeds the permitted use, you will need to obtain permission directly from the copyright holder. To view a copy of this licence, visit http://creativeco mmons.org/licenses/by/4.0/. The Creative Commons Public Domain Dedication waiver (http://creativecommons.org/publicdomain/ zero/1.0/) applies to the data made available in this article, unless otherwise stated in a credit line to the data. 
diagnostic values of the test between groups of clinical characteristics.

\section{Main text \\ Materials and methods \\ Patients and samples}

A total of 125 newly diagnosed adenocarcinoma, clinical-stage IIIB-IV NSCLC patients were selected for this study at Cho Ray hospital from Jan-2016 to August-2019 (approval number 212-BVCR-HDDD). Patients were asked for participation and signed consent forms before collecting samples for EGFR mutation analysis $(5 \mathrm{~mL}$ of peripheral blood and matched tumor tissues after confirming histology assessments). Among them, blood samples of 69 patients were collected on the same day of performing tumor biopsy procedures. Whereas in 29 other cases, blood samples were obtained after 1-4 cycles of chemo-radiotherapy (1-7 weeks after diagnosis). In 27 patients who had undergone tumor resection, blood samples were collected within 2 weeks after surgery. No one has been treated with targeted therapies like EGFR tyrosine kinase inhibitors before the mutation testing. The clinical information such as Ecog PS (Cooperative oncology group performance status), smoking habit, clinicalstage, organ metastasis, and tumor size was selected from the medical records.

\section{Genomic DNA extraction from tumor tissue and EGFR analysis}

The genomic DNA (gDNA) was extracted from 3 sections of formalin-fixed paraffin-embedded (FFPE) tumor tissue samples using QIAamp DNA FFPE Tissue kit (Cat No./ID: 56404) according to the instruction of the manufacturer (Qiagen, Hilden, Germany). Concentration and purity of gDNA were measured by NanoDrop 8000 Spectrophotometer (Thermo Scientific, USA) and adjusted to $2 \mathrm{ng} / \mu \mathrm{l}$ before sequencing. EGFR mutations (exon 19 deletion-EGFR ${ }^{\mathrm{E} 19 \mathrm{del}}$, a threonine-to-methionine point mutation in exon $20-E G F R^{\mathrm{T} 790 \mathrm{M}}$, a leucine-to-arginine point mutation in exon $21-E G F R^{\mathrm{L} 858 \mathrm{R}}$ ) were detected by pyrosequencing method using Therascreen EGFR Pyro kit (Cat No./ID: 971480) according to the instructions of the manufacturer (Qiagen, Hilden, Germany).

\section{Circulating free DNA extraction from plasma and EGFR analysis}

The blood samples were prepared and used for cfDNA extraction on the QIAsymphony machine, as described in previous work [10]. EGFR mutations in cfDNA were detected by the scorpion ARMS method, the Therascreen EGFR Plasma RGQ PCR kit (Cat No./ID: 870311), performed on the RotorGene Q 5Plex HRM platform according to the manufacturer's instructions (Qiagen, Hilden, Germany).

\section{Statistical analysis}

Fisher's exact test was used to compare the relative frequencies between groups. The concordance rate between the EGFR plasma and the EGFR tumor tests was determined by the Kappa statistic [11]. The mutation results in the tumor tissue were used as the standard reference for calculating sensitivity, specificity, positive and negative predictive values of EGFR plasma test. Variables with $P$ value $\leq 0.25$ in sensitivity comparing were selected to use in the multivariable analysis by logistic regression. The influential factors for the sensitivity were identified and assessed by the odds ratio (OR) with a 95\% confidence interval $(95 \% \mathrm{CI})$. All data analyses were done by $\mathrm{R}$ statistical software v.3.5.1 (R foundation, 1020 Vienna, Austria). $P<0.05$ was considered statistically significant.

\section{Results \\ Baseline characteristics}

All of 125 cases enrolled in this study were newly-diagnosed, clinical-stage IIIB-IV adenocarcinoma with a median age of 59 (95\%CI 57-61) years. On general examination, 24 cases $(19.2 \%)$ were scored $\geq 2$ with the Ecog PS criteria. All of the female patients (37 subjects) were never smokers, while 71 of $88(80.7 \%)$ male patients were smokers or ever smokers.

The diagnostic imaging results just before plasmamutation testing indicated that $83(66.4 \%)$ patients have the lymph-node metastasis while 39 (31.2\%) cases have the pleural effusion. Lung metastasis and distant metastasis were observed in $39(31.2 \%)$ and 100 (80.0\%) cases, respectively. Of which, brain, bone, liver, and other metastasis (including stomach, adrenal, spleen, thyroid gland, and prostate metastases) were observed in $36(28.8 \%), 37$ (29.6\%), 27 (21.6\%), and $49(39.2 \%)$ cases, respectively. Eighty-two (65.6\%) cases have tumor size $>5 \mathrm{~cm}$.

\section{EGFR status in tumor tissue and plasma samples}

EGFR mutations were detected in tumor tissue and plasma of $65(52.0 \%)$ and $50(40.0 \%)$ cases, respectively $(P=0.028$, Additional file 1: Table S1). Patients who have undergone chemo-radiotherapy and/or tumor removal have the lower frequency of EGFR mutations in tumor tissue $(41.0 \%)$ and plasma $(25.0 \%)$ compared to others $(60.8 \%, P=0.028$; and $52.2 \%, P=0.002$, respectively, Additional file 2: Table S2). Besides, in both tumor tissue and plasma samples, EGFR mutations occurred with a higher rate in non-smokers and female patients compared to the remaining groups $(P<0.001)$. 
The diagnostic values of EGFR plasma test and influential factors for sensitivity

Among 125 patients, 108 cases have the same results in plasma and matched tumor tissue samples resulting in a pooled concordance rate of $86.4 \%$ between methods (Additional file 3: Table S3). The sensitivity and specificity of the plasma test reached $75.4 \%$ and $98.3 \%$, respectively. Among the clinical sub-groups, the concordance rate and the sensitivity of EGFR plasma test were higher in patients with Ecog PS $\geq 2$, pleural effusion, and tumor size $>5 \mathrm{~cm}$ compared to others but not with statistical significance $(P>0.05$, Table 1$)$. Notably,

Table 1 The diagnostic values of EGFR plasma test between groups

\begin{tabular}{|c|c|c|c|c|c|c|}
\hline \multirow[t]{2}{*}{ Variable } & \multicolumn{2}{|l|}{ Concordance } & \multicolumn{2}{|l|}{ Sensitivity } & \multicolumn{2}{|l|}{ Specificity } \\
\hline & Percentage (\%) & $P$-value & Percentage (\%) & $P$-value & Percentage (\%) & $P$-value \\
\hline \multicolumn{7}{|l|}{ Mutation type } \\
\hline$E G F R^{E 19 d e l}(\mathrm{n}=125)$ & 92.8 & 0.212 & 77.5 & 0.472 & 100.0 & 0.360 \\
\hline$E G F R^{L 858 R}(n=125)$ & 95.2 & & 78.2 & & 99.0 & \\
\hline \multicolumn{7}{|l|}{ Age } \\
\hline$\geq 59(n=57)$ & 87.7 & 0.694 & 79.3 & 0.510 & 96.4 & 0.467 \\
\hline$<59(n=68)$ & 85.3 & & 72.2 & & 100.0 & \\
\hline \multicolumn{7}{|l|}{ Gender } \\
\hline Female $(n=37)$ & 83.8 & 0.290 & 80.0 & 0.424 & 100.0 & 0.714 \\
\hline Male $(n=88)$ & 87.5 & & 71.4 & & 98.1 & \\
\hline \multicolumn{7}{|l|}{ Ecog PS } \\
\hline $0-1(n=101)$ & 84.2 & 0.191 & 70.6 & 0.159 & 98.0 & 0.833 \\
\hline$\geq 2(n=24)$ & 95.8 & & 92.9 & & 100.0 & \\
\hline \multicolumn{7}{|l|}{ Smoking status } \\
\hline $\mathrm{No}(\mathrm{n}=54)$ & 87.0 & 0.428 & 84.1 & 0.018 & 100.0 & 0.652 \\
\hline Yes $(n=71)$ & 85.9 & & 57.1 & & 98.0 & \\
\hline \multicolumn{7}{|l|}{ Clinical stage } \\
\hline$\| I B(n=6)$ & 83.3 & 0.592 & 66.7 & 0.578 & 100.0 & 0.950 \\
\hline IV $(n=119)$ & 86.6 & & 75.8 & & 98.3 & \\
\hline \multicolumn{7}{|l|}{ Lung metastasis } \\
\hline No $(n=86)$ & 84.9 & 0.334 & 73.3 & 0.404 & 97.6 & 0.683 \\
\hline Yes $(n=39)$ & 89.7 & & 80.0 & & 100.0 & \\
\hline \multicolumn{7}{|l|}{ Lymph-node } \\
\hline No $(n=42)$ & 85.7 & 0.874 & 75.0 & 0.956 & 100.0 & 0.700 \\
\hline Yes $(n=83)$ & 86.8 & & 75.6 & & 97.6 & \\
\hline \multicolumn{7}{|l|}{ Pleural effusion } \\
\hline No $(n=86)$ & 83.7 & 0.155 & 70.5 & 0.152 & 97.6 & 0.700 \\
\hline Yes $(n=39)$ & 92.3 & & 85.7 & & 100.0 & \\
\hline \multicolumn{7}{|l|}{ Distant metastasis } \\
\hline No $(n=25)$ & 88.0 & 0.545 & 80.0 & 0.461 & 100.0 & 0.833 \\
\hline Yes $(n=100)$ & 86.0 & & 74.0 & & 98.0 & \\
\hline \multicolumn{7}{|l|}{ Tumor size } \\
\hline$\leq 5 \mathrm{~cm}(\mathrm{n}=43)$ & 84.2 & 0.233 & 70.0 & 0.164 & 97.0 & 0.700 \\
\hline$>5 \mathrm{~cm}(\mathrm{n}=82)$ & 90.7 & & 84.0 & & 100.0 & \\
\hline \multicolumn{7}{|c|}{ Treatment: chemo-radiotherapy and/or surgery } \\
\hline No $(n=69)$ & 91.3 & 0.076 & 85.7 & 0.009 & 100.0 & 0.362 \\
\hline Yes $(n=56)$ & 80.4 & & 56.5 & & 97.0 & \\
\hline \multicolumn{7}{|l|}{ Treatment/Smoking status } \\
\hline $\mathrm{No} / \mathrm{No}(\mathrm{n}=34)$ & 91.2 & 0.418 & 90.3 & 0.004 & 100.0 & 0.483 \\
\hline No/Yes or Yes/No $(n=55)$ & 87.3 & & 70.8 & & 100.0 & \\
\hline Yes/Yes $(n=36)$ & 80.6 & & 40.0 & & 96.2 & \\
\hline
\end{tabular}

Significant values are shown in italic 
we found that sensitivity of EGFR plasma test is higher in non-smokers (84.1\%) compared to smokers $(57.1 \%$, $P=0.018)$, and higher in untreated patients $(85.7 \%)$ compared to others $(56.5 \%, P=0.009$, Table 1$)$. Furthermore, the highest sensitivity was archived in nonsmoking untreated patients $(90.3 \%)$ while the lowest value was observed in smoking treated subjects $(40.0 \%$, $P=0.004)$. In the multivariable analysis, smoking habit ( $\mathrm{OR}=0.24, P=0.019)$ and treatment history as chemoradiotherapy and/or surgery $(\mathrm{OR}=0.36, P=0.047)$ were identified as independent factors for the lower sensitivity of EGFR plasma test (Table 2).

\section{Discussion}

Previous studies have shown that the concordance rate and sensitivity of EGFR plasma test are different between centers depend on the technique used and pre-analytic factors $[1,7,9]$. The deep-sequencing, digital polymerase chain reaction ( $\mathrm{dPCR})$, and scorpion ARMS are the best methods in detecting mutations in cfDNA. Of these technologies, digital PCR and scorpion ARMS are widely-used up to date because of the low limit of detection (0.05-0.1\%), convenience, rapidity, and low cost [12].

In this study, we used the scorpion ARMS method to detect EGFR mutations in plasma samples and showed a high agreement with the tumor tissues together with a moderate sensitivity and excellent specificity (Additional file 3: Table S3). The limited sensitivity (75\%) is due to nearly $25 \%$ of the cases with false-negative results in the plasma. It is worth noting that EGFR mutations in plasma are detected by the scorpion ARMS method that has a lower limit of detection than the pyrosequencing method $(\approx 5 \%)$ [13]. We performed a literature review and noted that the false-negative phenomenon also is observed in other studies used scorpion ARMS method [14-28], dPCR [5, 6, 29], and

\begin{tabular}{llc}
$\begin{array}{l}\text { Table } 2 \text { Influential factors } \\
\text { in multivariable analysis }\end{array}$ & for the & sensitivity \\
\hline Variable & OR (95\%Cl) & P-value \\
\hline Ecog PS: $\geq 2$ versus 0-1 & $4.81(0.59-46.80)$ & 0.176 \\
Smoking habit: Yes versus No & $0.24(0.07-0.79)$ & 0.019 \\
Pleural effusion: Yes versus No & $1.09(0.26-4.56)$ & 0.911 \\
Tumor size: $>5$ cm versus $\leq 5$ cm & $1.79(0.51-6.32)$ & 0.366 \\
Treatment history: Yes versus No & $0.36(0.10-0.91)$ & 0.047 \\
\hline
\end{tabular}

In the logistic regression analysis, patients with EGFR mutations in both tumor tissue and plasma were coded 1 , while the positive cases only in the tumor tissue were coded 0 ; other factors were coded 1: Ecog PS $\geq 2$, smoking habit $=$ yes, pleural effusion $=$ yes, tumor size $>5 \mathrm{~cm}$, and treatment history = yes; the remaining groups of factors were coded 0

Significant values are shown in italic even ultra-deep sequencing methods $[2-4,30]$. Therefore, the EGFR plasma sensitivity might be affected by the other factors besides the technique influences.

Our data indicated that the concordance rate and sensitivity of EGFR plasma test are improved in untreated patients (Table 1), and higher than values in previous studies used the same method (Fig. 1). It is easy to see that these studies used the column-based method in cfDNA extraction [14-28] that lead to the low-yield of cfDNA and low sensitivity [9]. In the study, we also found that smoking habits influence the presence of EGFR mutations in plasma (Additional file 2: Table S2) and thus affect the sensitivity of the test (Table 1 ). The combination of this factor with induction therapy as chemo-radiotherapy and/or tumor removal before mutation testing resulted in very low sensitivity, whereas the highest value was archived in those without these two factors (Table 1). Finally, the independent negative impact of these factors on sensitivity was confirmed by the multivariable analysis (Table 2).

The negative impact of treatment history on EGFR plasma sensitivity can be explained by the reduction of mutant-cell derived cfDNA fraction. Guo $\mathrm{N}$ reported that $92 \%$ of mutation frequencies decrease within two days after surgery [31]. Likewise, a deep clearance of EGFR mutant alleles after chemotherapy was showed in the study of Mok $\mathrm{T}$ [32]. Taniguchi $\mathrm{K}$ and Bai $\mathrm{H}$ demonstrated that both EGFR-mutated and non-mutated cell clones coexist in the same tumor [33, 34]. Because of more sensitivity to chemotherapy, the EGFR-mutated cancer cells are eliminated faster than non-mutated cells leading to the shift of EGFR status from positive to negative after chemotherapy [33, 34]. Zhang $S$ noted that chemotherapy is an independent factor for the presence of EGFR mutations in the plasma of NSCLC patients [35].

The association of smoking with the low EGFR frequency in tumor tissue and plasma samples of NSCLC has been shown in many studies $[16,18,20,36]$. Nevertheless, the underlying mechanism of this phenomenon is unclear to date. Previous studies have shown that smoking is related to an elevated tumor mutational burden (TMB) in NSCLC [37-41]. Moreover, the higher TMB is associated with tumor protein p53 (TP53) alterations, and negatively associated with EGFR mutations [41]. Other studies emphasized the association of smoking habit with the presence of TP53 and Kirsten rat sarcoma viral oncogene (KRAS) mutations rather than EGFR mutations [42-44]. We assume that in smoking NSCLC patients, EGFR mutation is not the key driver, and the EGFR mutant subclone might present at a low fraction in the tumor content. Therefore, the amount of tumor DNA released by these cells into the blood is limited (it might 

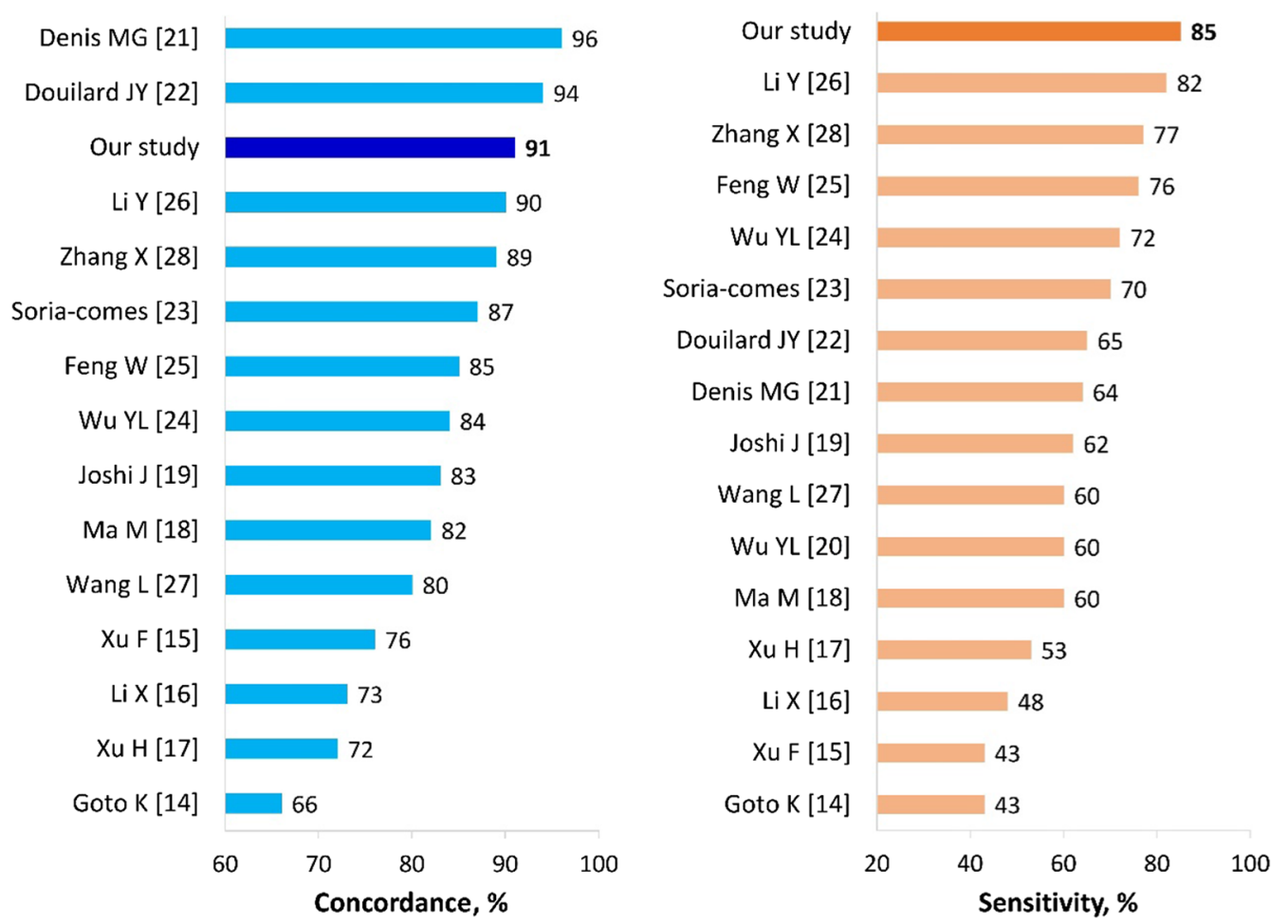

Fig. 1 The concordance rate and sensitivity of EGFR plasma test in the studies used scorpion ARMS method

be below $0.05 \%$ of the total cfDNA amount). That is the cause of the low sensitivity of plasma testing.

In clinical practice, these results help the clinicians to define subgroups of patients with different sensitivity of $E G F R$ plasma test. In those confirmed with lung cancer by the diagnostic imaging and protein tumor markers but failure with the biopsy procedure, or inadequate tumor tissue for EGFR mutation analysis, clinical doctors should require the mutation testing in plasma before starting chemo-radiotherapy. In other cases, mutation analysis in the resected tumors should be done first for the patients who have undergone surgery.

\section{Conclusion}

The results of this study showed that the sensitivity of the $E G F R$ plasma test is lower in smoking treated patients compared to others. Besides, smoking habit and induction therapy as chemo-radiotherapy and/or surgery might be the independently influential factors for the sensitivity.

\section{Limitations}

This study highlights the negative impact of smoking habit and chemo-radiotherapy and/or surgery on the sensitivity of the EGFR plasma test in NSCLC.
However, this is just an observation from a singlecenter study. Besides, the sample size in the study is still limited. Further research on a large cohort should be done to confirm this finding. In those studies, one same technique should be used for both tumor and plasma testing to clarify the association of clinical factors with sensitivity.

\section{Supplementary information}

Supplementary information accompanies this paper at https://doi. org/10.1186/s13104-020-05209-9.

Additional file 1: Table S1. Frequency of EGFR mutations in tumor tissue and plasma.

Additional file 2: Table S2. EGFR mutation status between groups of patient's characteristics.

Additional file 3: Table S3. The diagnostic values of EGFR plasma test.

\section{Abbreviations}

ARMS: Amplification-refractory mutation system; cfDNA: Circulating free DNA; dPCR: Digital polymerase chain reaction; EGFR: Epidermal growth factor receptor; Ecog PS: Cooperative oncology group performance status; FFPE: Formalinfixed paraffin-embedded; gDNA: Genomic DNA; KRAS: Kirsten rat sarcoma viral oncogene; NSCLC: Non-small cell lung cancer; OR: Odds ratio; TMB: Tumor mutational burden; TP53: Tumor protein p53; 95\%Cl: 95\% Confidence interval.

\section{Acknowledgements \\ None.}




\section{Authors' contributions}

NST and PTT are senior authors who contributed to study design; PTT, LAT and LVT selected patients for the study and collected clinical data; Tran VT, Ho TT, Pho SP, Nguyen TB, Pham TTB and NHT collected samples and performed mutation analysis; PTT, NST and TBT performed the data analysis and wrote the manuscript. All authors read and approved the final manuscript.

\section{Funding}

None.

\section{Availability of data and materials}

The datasets generated during and/or analysed during the current study are available from the corresponding author on reasonable request.

\section{Ethics approval and consent to participate}

This study was considered and approved by the Ethics Committees of Cho Ray Hospital (Approval Number: 212-BVCR-HDDD). Patients were asked for participation in the study and signed consent forms before collecting blood samples.

\section{Consent to publish}

Not applicable.

\section{Competing interests}

The authors declared that no conflicts of interest exist.

\section{Author details}

${ }^{1}$ The Laboratory D Unit, Clinical Cancer Center, Cho Ray Hospital, 201B Nguyen Chi Thanh Street, Dist. 5, Ho Chi Minh City 700000, Vietnam. ${ }^{2}$ Faculty of Biology-Biotechnology, University of Science, VNU-HCM, Ho Chi Minh City 700000, Vietnam. ${ }^{3}$ Department of the Vice Minister, Ministry of Health, Hanoi City 100000, Vietnam. ${ }^{4}$ Department of Chemo-Radiotherapy, Clinical Cancer Center, Cho Ray Hospital, Ho Chi Minh City 700000, Vietnam. ${ }^{5}$ Department of Thoracic Disease, Cho Ray Hospital, Ho Chi Minh City 700000, Vietnam. ${ }^{6}$ Department of Clinical Pathology, Cho Ray Hospital, Ho Chi Minh City 700000, Vietnam.

Received: 19 May 2020 Accepted: 28 July 2020

Published online: 03 August 2020

\section{References}

1. Qian X, Liu J, Sun Y, et al. Circulating cell-free DNA has a high degree of specifcity to detect exon 19 deletions and the single-point substitution mutation L858R in non-small cell lung cancer. Oncotarget. 2016;7(20):29154-65.

2. Veldore $\mathrm{VH}$, Choughule $\mathrm{A}$, Routhu T, et al. Validation of liquid biopsy: plasma cell-free DNA testing in clinical management of advanced nonsmall cell lung cancer. Lung Cancer. 2018;9:1-11.

3. Paweletz CP, Sacher AG, Raymond CK, et al. Bias-corrected targeted nextgeneration sequencing for rapid, multiplexed detection of actionable alterations in cell-free DNA from advanced lung cancer patients. Clin Cancer Res. 2016;22(4):915-22.

4. Newman AM, Lovejoy AF, Klass DM, et al. Integrated digital error suppression for improved detection of circulating tumor DNA. Nat Biotechnol. 2016;34(5):547-55.

5. Lee JY, Qing X, Xiumin W, et al. Longitudinal monitoring of EGFR mutations in plasma predicts outcomes of NSCLC patients treated with EGFR TKIs: Korean lung cancer consortium (KLCC-12-02). Oncotarget. 2016:7(6):6984-93.

6. Sacher AG, Paweletz C, Dahlberg SE, et al. Prospective validation of rapid plasma genotyping for the detection of EGFR and KRAS mutations in advanced lung cancer. JAMA Oncol. 2016;2(8):1014-22.

7. Trigg RM, Martinson LJ, Parpart-Li S, Shaw JA. Factors that influence quality and yield of circulating-free DNA: a systematic review of the methodology literature. Heliyon. 2018;4(7):e00699.

8. Dessel LF, Vitale SR, Helmijr JCA, et al. High-throughput isolation of circulating tumor DNA: a comparison of automated platforms. Mol Oncol. 2019;13(2):392-402.
9. Nakashima C, Sato A, Abe T, et al. Automated DNA extraction using cellulose magnetic beads can improve EGFR point mutation detection with liquid biopsy by efficiently recovering short and long DNA fragments. Oncotarget. 2018;9(38):25181-92.

10. Phan TT, Tran BT, Nguyen ST, et al. EGFR plasma mutation in prediction models for resistance with EGFR TKI and survival of non-small cell lung cancer. Clin Trans Med. 2019:8:4.

11. McHugh ML. Interrater reliability: the kappa statistic. Biochem Med. 2012;22(3):276-82

12. Siravegna G, Marsoni S, Siena S, Bardelli A. Integrating liquid biopsies into the management of cancer. Nat Rev Clin Oncol. 2017;14(9):531-48.

13. Rapisuwon S, Vietsch EE, Wellstein A. Circulating biomarkers to monitor cancer progression and treatment. Comput Struct Biotechnol J. 2016:14:211-22.

14. Goto $K$, Ichinose $Y$, Ohe $Y$, et al. Epidermal growth factor receptor mutation status in circulating free DNA in serum: from IPASS, a phase III study of gefitinib or carboplatin/paclitaxel in non-small cell lung cancer. J Thorac Oncol. 2012;7(1):115-21.

15. Xu F, Wu J, Xue C, et al. Comparison of different methods for detecting epidermal growth factor receptor mutations in peripheral blood and tumor tissue of non-small cell lung cancer as a predictor of response to gefitinib. Onco Targets Ther. 2012;5:439-47.

16. Li X, Ren R, Ren S, et al. Peripheral blood for epidermal growth factor receptor mutation detection in non-small cell lung cancer patients. Transl Oncol. 2014;7(3):341-8.

17. $\mathrm{Xu} \mathrm{H}$, Baidoo AA, Su S, et al. A comparison of EGFR mutation status in tissue and plasma cell-free DNA detected by ADx-ARMS in advanced lung adenocarcinoma patients. Transl Lung Cancer Res. 2019;8(2):135-43.

18. Ma M, Shi C, Qian J, et al. Comparison of plasma and tissue samples in epidermal growth factor receptor mutation by ARMS in advanced nonsmall cell lung cancer. Gene. 2016;591(1):58-64.

19. Joshi J, Raval A, Desai U, et al. EGFR mutation analysis in non-small cell lung carcinoma patients: a liquid biopsy approach. Ind J Clin Biochem. 2019. https://doi.org/10.1007/s12291-019-00864-7.

20. Wu YL, Sequist LV, Hu CP, et al. EGFR mutation detection in circulating cell-free DNA of lung adenocarcinoma patients: analysis of LUX-Lung 3 and 6. Br J Cancer. 2017:116(2):175-85.

21. Denis MG, Lafourcade MP, Garff GL, et al. Circulating free tumorderived DNA to detect EGFR mutations in patients with advanced NSCLC: French subset analysis of the ASSESS study. J Thorac Dis. 2019:11(4):1370-8

22. Douillard JY, Ostoros G, Cobo M, et al. Gefitinib treatment in EGFR mutated caucasian NSCLC circulating free tumor DNA as a surrogate for determination of EGFR status. J Thorac Oncol. 2014;9(9):1345-53.

23. Soria-Comes T, Palomar-Abril V, Ureste MM, et al. Real-world data of the correlation between EGFR determination by liquid biopsy in non-squamous non-small cell lung cancer (NSCLC) and the EGFR profile in tumor biopsy. Pathol Oncol Res. 2020;26(2):845-51.

24. Wu YL, Lee V, Liam CK, et al. Clinical utility of a blood-based EGFR mutation test in patients receiving first-line erlotinib therapy in the ENSURE, FASTACT-2, and ASPIRATION studies. Lung Cancer. 2018;26:1-8.

25. Feng W, Gu W, Zhao N, et al. Comparison of the SuperARMS and droplet digital PCR for detecting EGFR mutation in ctDNA from NSCLC patients. Transl Oncol. 2018;11(2):542-5.

26. Li Y, Xu H, Su S, et al. Clinical validation of a highly sensitive assay to detect EGFR mutations in plasma cell-free DNA from patients with advanced lung adenocarcinoma. PLoS ONE. 2017;12(8):e0183331.

27. Wang L, Guo Q, Yu W, et al. Quantification of plasma EGFR mutations in patients with lung cancers: comparison of the performance of ARMS-Plus and droplet digital PCR. Lung Cancer. 2017;114:31-7.

28. Zhang X, Chang N, Yang G, et al. A comparison of ARMS-Plus and droplet digital PCR for detecting EGFR activating mutations in plasma. Oncotarget. 2017;8(67):112014-23.

29. Yung TK, Chan KC, Mok TS, et al. Single-molecule detection of epidermal growth factor receptor mutations in plasma by microfluidics digital PCR in non-small cell lung cancer patients. Clin Cancer Res. 2009:15(6):2076-84.

30. Reckamp KL, Melnikova VO, Karlovich C, et al. A Highly sensitive and quantitative test 30.platform for detection of NSCLC EGFR mutations in urine and plasma. J Thorac Oncol. 2016;11(10):1690-700. 
31. Guo N, Lou F, Ma Y, et al. Circulating tumor DNA detection in lung cancer patients before and after surgery. Sci Rep. 2016;6:33519. https://doi. org/10.1038/srep33519.

32. MokT, Wu YL, Lee JS, et al. Detection and dynamic changes of EGFR mutations from circulating tumor DNA as a predictor of survival outcomes in NSCLC patients treated with first-line intercalated erlotinib and chemotherapy. Clin Cancer Res. 2015;21(14):3196-203.

33. Taniguchi K, Okami J, Kodama K, et al. Intratumor heterogeneity of epidermal growth factor receptor mutations in lung cancer and its correlation to the response to gefitinib. Cancer Sci. 2008;99(5):929-35.

34. Bai H, Wang Z, Chen $\mathrm{K}$, et al. Influence of chemotherapy on EGFR mutation status among patients with non-small-cell lung cancer. J Clin Oncol. 2012;30(25):3077-83.

35. Zhang S, Zhu L, Chen X, et al. ctDNA assessment of EGFR mutation status in Chinese patients with advanced non-small cell lung cancer in realworld setting. J Thorac Dis. 2018;10(7):4169-77.

36. Zhang YL, Yuan JQ, Wang KF, et al. The prevalence of EGFR mutation in patients with non-small cell lung cancer: a systematic review and metaanalysis. Oncotarget. 2016;7(48):78985-93.

37. Alexandrov LB, Ju YS, Haase $K$, et al. Mutational signatures associated with tobacco smoking in human cancer. Science. 2016;354(6312):618-22.

38. Nagahashi M, Sato S, Yuza K, et al. Common driver mutations and smoking history affect tumor mutation burden in lung adenocarcinoma. J Surg Res. 2018;230:181-5.
39. Chae YK, Davis AA, Agte S, et al. Clinical implications of circulating tumor DNA tumor mutational burden (ctDNA TMB) in non-small cell lung cancer. Oncologist. 2019;24(6):820-8.

40. Yu XJ, Chen G, Yang J, et al. Smoking alters the evolutionary trajectory of non-small cell lung cancer. Exp Ther Med. 2019;18(5):3315-24.

41. Willis C, Fiander M, Tran D, et al. Tumor mutational burden in lung cancer: a systematic literature review. Oncotarget. 2019;10(61):6604-22.

42. Subramanian J, Govindan R. Molecular genetics of lung cancer in people who have never smoked. Lancet Oncol. 2008;9(7):676-82.

43. Liu X, Lin XJ, Wang CP, et al. Association between smoking and p53 mutation in lung cancer: a meta-analysis. Clin Oncol. 2014;26(1):18-24.

44. Chapman AM, Sun KY, Ruestow P, Cowan DM, Madl AK. Lung cancer mutation profile of EGFR, ALK, and KRAS: meta-analysis and comparison of never and ever smokers. Lung Cancer. 2016;102:122-34.

\section{Publisher's Note}

Springer Nature remains neutral with regard to jurisdictional claims in published maps and institutional affiliations.
Ready to submit your research? Choose BMC and benefit from:

- fast, convenient online submission

- thorough peer review by experienced researchers in your field

- rapid publication on acceptance

- support for research data, including large and complex data types

- gold Open Access which fosters wider collaboration and increased citations

- maximum visibility for your research: over $100 \mathrm{M}$ website views per year

At BMC, research is always in progress.

Learn more biomedcentral.com/submissions 